\title{
PR-4. ABOUT POSSIBILITY OF USING NANOPARTICLES BASED ON GADOLINIUM COMPOUNDS IN PREPARATIONS FOR DIAGNOSTICS OF ONCOLOGICAL DISEASES
}

\author{
I. A. Belova, A. S. Grodsky, V. S. Makulova, A. O. Klyonova, A. I. Semakina \\ D. Mendeleev University of Chemical Technology of Russia, \\ Miusskaya sq., 9, 125047, Russia \\ E-mail: irinabelova@yandex.ru
}

At the present time different contrasting agents are used for magnetic resonance imaging in clinical practice. They allow carrying out a molecular imaging that let us observe processes, which are taking place at molecular and cellular levels in living organism. Design and development of new contrasting agents for MRI is a fast-growing research area at the interface of several sciences - chemistry, biochemistry, biophysics, molecular biology and pharmacology.

There are several requirements for contrasting agents: creation a strong MR contrasting, thermodynamic affinity to water, a possibility of long-term storage for clinical use, low toxicity and high stability in vivo and rapid egestion of agent from organism.

Predominantly, paramagnetic agents are used as contrast ones. Particularly, among these are agents, containing gadolinium compounds, because they have a large magnetic moment and unpaired electrons. Application of high-dispersity gadolinium oxide is one of the most promising courses in MRI-contrasting area, because it is characterized by higher value of spin-lattice relaxation constant in comparison with $\mathrm{Gd}^{3+}$ chelate complex, which allows getting significant intensification of NMR signals [1].

The purpose of this study was synthesis of water-base nanodispersions of oxygen-containing gadolinium compounds and determination of their colloid-chemical properties, which are responsible for aggregative stability.

Hydrosols were obtained via condensation method at room temperature in accordance with method, reported in previous study [2]. The hydrosols' concentration of dispersed phase (in conversion to $\mathrm{Gd}_{2} \mathrm{O}_{3}$ ) reached $20 \mathrm{~g} / 1$. It was determined that the hydrosols were stable at rather wide range of dispersion medium $\mathrm{pH}(7,2-9,5 \mathrm{pH}$ points).

Electrophoretic measurements showed that sol's particles in this $\mathrm{pH}$ range had positive charge and, according to calculations by Helmholtz-Smoluchowski equation, their electrokinetic potential was equal $24-28 \mathrm{mV}$, so we could conclude that they were heavily charged. Therefore, electrostatic factor influences significantly on the sols' aggregative stability.

Developed synthetic methods of such nanodispersions, the same as undertaken study of their colloidchemical properties, characteristics and parameters, allow using them for obtaining promising and highlyeffective locally produced next-generation's preparations for treatment and diagnostics of oncological diseases.

\section{References}

1. Мешалкин Ю. П., Бгатова Н. П. Перспективы и проблемы использования неорганических наночастиц в онкологии (Обзор) // J. Sib. Fed. Univ. Biol. 2008. Vol. 3, № 2008 1. P. 248-268.

2. Malova A. V., Grodskii A. S., Belova I. A. Synthesis and aggregation stability of europium oxohydroxide hydrosols // Colloid J. Pleiades Publishing, 2016. Vol. 78, № 4. P. 478-484.

The work was supported by D. Mendeleev University of Chemical Technology of Russia (Project № 013-2018). 